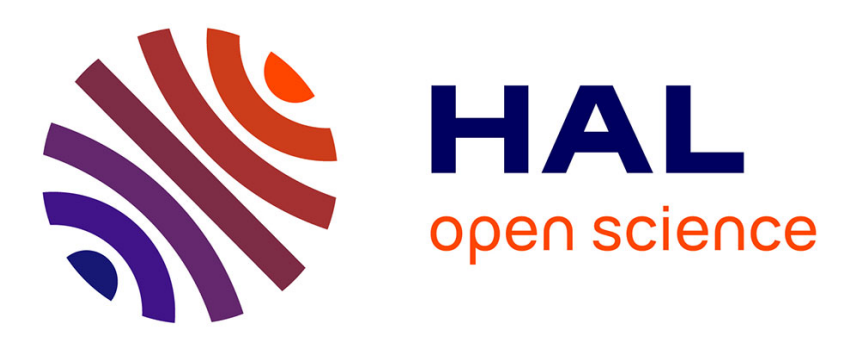

\title{
Fracture study of organic-inorganic coatings using nanoindentation technique
}

Sylvie Etienne-Calas, Agnès Duri, P. Etienne

\section{To cite this version:}

Sylvie Etienne-Calas, Agnès Duri, P. Etienne. Fracture study of organic-inorganic coatings using nanoindentation technique. Journal of Non-Crystalline Solids, 2004, 344 (1-2), pp.60-65. 10.1016/j.jnoncrysol.2004.07.029 . hal-02682626

\section{HAL Id: hal-02682626 \\ https://hal.inrae.fr/hal-02682626}

Submitted on 1 Jun 2020

HAL is a multi-disciplinary open access archive for the deposit and dissemination of scientific research documents, whether they are published or not. The documents may come from teaching and research institutions in France or abroad, or from public or private research centers.
L'archive ouverte pluridisciplinaire HAL, est destinée au dépôt et à la diffusion de documents scientifiques de niveau recherche, publiés ou non, émanant des établissements d'enseignement et de recherche français ou étrangers, des laboratoires publics ou privés.

\section{다(1)(2)}

Distributed under a Creative Commons Attribution - ShareAlikel 4.0 International 


\title{
Fracture study of organic-inorganic coatings using nanoindentation technique
}

\author{
S. Etienne-Calas *, A. Duri, P. Etienne \\ Laboratoire des verres, UMR 5587, Université Montpellier 2, Place E. Bataillon, 34095 Montpellier cedex 05, France
}

\begin{abstract}
The mechanical response of different coating-substrate systems are investigated using the nanoindentation technique. From the load-penetration depth curves, we determined the hardness $H_{\mathrm{c}}$ and the elastic modulus $E_{\mathrm{c}}$ of the coatings. Moreover, as the force increases, cracks, delamination and chipping can appear. These effects induce discontinuities on the indentation curves. Measuring crack lengths or calculating the dissipated energy during indentation allows the determination of residual stress in the coating and interface toughness. Two kinds of organic-inorganic coatings on different substrates (silicon and glass) are studied. The coatings were prepared by the sol-gel process and deposited using the spin-coating technique. The first coating is a mixture of methyltrimethoxysilane, colloidal silica and tetraethylorthosilicate and the second one is based on 3-(trimethoxysilyl)propyl-methacrylate. The first one reveals better general mechanical properties (lower residual stress, better adhesion, higher interfacial toughness) on silicon than on glass. For the second one, the elastic modulus and hardness are comparable with those of polymers. In contrast, coating toughness is lower.

(C) 2004 Published by Elsevier B.V.
\end{abstract}

PACS: 81.20.F; 68.60.B; 81.07.Pr

\section{Introduction}

Hybrid organic-inorganic coatings find applications in different domains, particularly in optics with nonreflecting, anti-abrasion, or scratch resistant surfaces [1] and in optoelectronics with integrated optical circuits [2]. Such coatings are fabricated by the sol-gel process. Compared with others processing techniques, the great interest of sol-gel process is its relative tailoring simplicity. It is now well known that organic-inorganic hybrid precursors are very effective materials for such applications. However, for an industrial use, mechanical prop01.

${ }^{*}$ Corresponding author. Tel.: +334671432 84; fax: +334675448 Calas). erties of the film and of the interface between film and substrates have to be known because they play a crucial role in coating efficiency and aging.

The nanoindentation technique is well known to permit the mechanical characterization of coating-substrate systems. The principle of the experiments is to indent the sample and to record the force as a function of the penetration depth. From the force-indentation depth curves, the hardness $H_{\mathrm{c}}$ and the elastic modulus $E_{\mathrm{c}}$ of the coatings are parameters classically obtained when the indentation depth is small compared to the coating thickness (about less than 10\%). As the force increases, cracks, delamination and chipping can appear. These effects induce discontinuities in the indentation curves. More recently, Malzbender and de With $[3,4]$ showed that, by measuring cracks length or by calculating the dissipated energy during indentation, others mechanical 
parameters such as residual stress in the film, fracture toughness of the coating, fracture toughness of the interface between coating and substrate can be determined.

In this paper, two kinds of organic-inorganic coatings are studied. The first one is based on 3-(trimethoxysilyl)propyl-methacrylate and is used in integrated optical circuits fabrication. The second kind of coating is a mixture of methyltrimethoxysilane, colloidal silica and tetraethylorthosilicate and is used to make antiabrasion films. The structure of these coatings are different: the first one is a copolymer with an inorganic part containing $\mathrm{Si}$ and $\mathrm{Zr}$ and an important organic network. The second one has a highly mineral structure with a network made only by siloxane bonds. Consequently, the mechanical behaviour of these systems is expected to be different. The aim of this work is to evidence such a difference by nanoindentation technique.

\section{Experimental}

Experiments are performed by using two kinds of hybrid organic-inorganic coatings. The first one (named A) contains $30 \%$ (weight) solids components and $70 \%$ solvents. The precursors are methyltrimethoxysilane (MTMOS, assay $>98 \%$ ), colloidal silica and tetraethylorthosilicate (TEOS, assay $>99 \%$ ). The weight amounts of MTMOS and colloidal silica are equal and the amount of TEOS is $2 \%$ (weight) of MTMOS quantity. The solvents are methanol (64\%), diethylene glycol $(34 \%), \mathrm{H}_{2} \mathrm{O}(1 \%)$ and ethanol $(1 \%)$. The coatings are deposited by spin-coating with free evaporation at $600 \mathrm{rpm}$. Two types of substrates are used: silicon wafers with $\mathrm{SiO}_{2}$ thermic layer (the coating-substrate system is named A1) and soda lime glasses (the coating-substrate system is named A2). Coating are dried a few minutes at $100^{\circ} \mathrm{C}$ to evaporate solvents and then heat treated at $250^{\circ} \mathrm{C}$ for $18 \mathrm{~h}$ to perform the coating densification.

The second kind of coating (named B) contains 3-(trimethoxysilyl)propylmetacrylate (MAPTMS, assay $99 \%$ ), zirconium (IV) $n$-propoxide $\left(\mathrm{Zr}\left(\mathrm{O}_{n} \mathrm{C}_{3} \mathrm{H}_{7}\right)_{4}\right.$ assay $70 \%$ in propanol), methacrylic acid (MAA, assay $>98 \%$ ) and $\mathrm{H}_{2} \mathrm{O}$ in molar ratio of 10:1.5:1.5:20. The Irgacure 1800 (CIBA) is used as photoinitiator to perform the polymerization of methacrylate bonds. The complete synthesis of this coating solution is described in Ref. [5]. Coatings are spin-coated with free evaporation at $1800 \mathrm{rpm}$ on silicon substrates (the system is named B). They are dried for $15 \mathrm{~min}$ at $60^{\circ} \mathrm{C}$ and UV cured for 30 s.

Indentation experiments are carried out using a home made instrumented microindentor [6]. The sample is maintained on a platen which can be moved horizontally and vertically with motors and also manually tilted to adjust the sample position perpendicular to the indentor. The indentor is a Berkovitch diamond. It is mounted on a force sensor working within the range $0-1000 \mathrm{mN}$ with an accuracy of $1 \mu \mathrm{N}$. The penetration depth is recorded using a displacement sensor measuring the displacement of a skirt surrounding the indentor. The sensor works within the range $0-10 \mu \mathrm{m}$ with an accuracy of $10 \mathrm{~nm}$. The displacement rate may be chosen between 0.1 and a few $\mu \mathrm{m} / \mathrm{min}$. An optical microscope allows us to observe the sample surface, before and after the indentation.

\section{Results}

Coatings thicknesses have been measured on cleaved sample using an optical microscope. The mean values are $5.1 \pm 0.2 \mu \mathrm{m}$ for A coating and $14.5 \pm 0.2 \mu \mathrm{m}$ for B coating.

\subsection{Hardness and elastic modulus}

The coating hardness $H_{\mathrm{c}}$ is defined by the ratio between the maximum load $F$ and the contact area $A$. Knowing precisely the indentor geometry (by calibration), this area can be expressed in terms of contact depth $h_{\mathrm{c}}$ directly determined from measurements.

The standard way to determine the coating elastic modulus $E_{\mathrm{c}}$ is by using the initial slope $S$ of the unloading curve $[7,8]$

$E_{\mathrm{r}}=\sqrt{\frac{\pi}{A}} \frac{S}{2}$. $[7,8]$

In this equation, $E_{\mathrm{r}}$ is the reduced modulus given by

$\frac{1}{E_{\mathrm{r}}}=\frac{1-v_{\mathrm{c}}^{2}}{E_{\mathrm{c}}}+\frac{1-v_{\mathrm{i}}^{2}}{E_{\mathrm{i}}}$,

where $v_{\mathrm{c}}, E_{\mathrm{c}}, v_{\mathrm{i}}, E_{\mathrm{i}}$ are the Poisson's ratio and the elastic modulus of coating and indentor.

To be sure that the substrate has no influence, the investigated depth corresponds to about $10 \%$ of the whole layer thickness. The results are, for A1, $E_{\mathrm{c}}=22 \pm 3 \mathrm{GPa}$ and $H_{\mathrm{c}}=2.0 \pm 0.2 \mathrm{GPa}, \quad \mathrm{A} 2, \quad E_{\mathrm{c}}=$ $17 \pm 2 \mathrm{GPa}$ and $H_{\mathrm{c}}=1.1 \pm 0.2 \mathrm{GPa}$ and $\mathrm{B}, E_{\mathrm{c}}=1.6 \pm$ $0.2 \mathrm{GPa}$ and $H_{\mathrm{c}}=0.21 \pm 0.05 \mathrm{GPa}$ (see Table 1 ).

\subsection{Coating toughness, residual stresses and interface toughness}

When the indentation load increases, several kinds of damage appear: cracks (originating from the edges of indentor), delamination (loss of contact between coating and substrate) and chipping (removal of coating segments). These events have been observed by microscopy and also associated to changes in the loading curves. They can be used to determine coating and interface 
Table 1

Results summary

\begin{tabular}{|c|c|c|c|c|c|c|c|c|c|c|}
\hline \multirow[t]{2}{*}{ Coating } & \multirow[t]{2}{*}{ System } & \multirow[t]{2}{*}{ Substrate } & \multirow[t]{2}{*}{ Thickness $(\mu \mathrm{m})$} & \multirow[t]{2}{*}{$E_{\mathrm{c}}(\mathrm{GPa})$} & \multirow[t]{2}{*}{$H_{\mathrm{c}}(\mathrm{GPa})$} & \multicolumn{2}{|c|}{$K_{\mathrm{Ic}}\left(\mathrm{MPa} \mathrm{m}^{1 / 2}\right)$} & \multicolumn{2}{|c|}{$K_{\text {int }}\left(\mathrm{MPam}^{1 / 2}\right)$} & \multirow[t]{2}{*}{$\sigma_{\mathrm{r}}(\mathrm{MPa})$} \\
\hline & & & & & & Geom. & Energ. & Geom. & Energ. & \\
\hline \multirow[t]{2}{*}{$\overline{\mathrm{A}}$} & A1 & $\mathrm{Si}$ & $5.1 \pm 0.2$ & $22 \pm 3$ & $2.0 \pm 0.2$ & $0.5 \pm 0.1$ & $0.7 \pm 0.1$ & $1.3 \pm 0.2$ & $1.5 \pm 0.2$ & $121 \pm 25$ \\
\hline & A2 & Glass & $5.1 \pm 0.2$ & $17 \pm 2$ & $1.1 \pm 0.2$ & $0.6 \pm 0.2$ & - & $0.31 \pm 0.05$ & - & $157 \pm 28$ \\
\hline $\mathrm{B}$ & B & $\mathrm{Si}$ & $14.5 \pm 0.2$ & $1.6 \pm 0.2$ & $0.37 \pm 0.06$ & $0.21 \pm 0.05$ & - & - & - & $-40 \pm 10$ \\
\hline
\end{tabular}

toughness and residual stresses in the coating. Basically, two kinds of approach are used: geometrical analysis and energetical one.

\subsubsection{Geometrical approach}

The most commonly used relationship between the length of the radials cracks $c$, the coating toughness $K_{\mathrm{Ic}}$ and the residual stresses $\sigma_{\mathrm{r}}$ is given by the relation $[9,10]$

$\chi \frac{F}{c^{3 / 2}}=K_{\mathrm{Ic}}-2 \sigma_{\mathrm{r}} \sqrt{\frac{c}{\pi}}$

where $\chi=0.016\left(E_{\mathrm{c}} / H_{\mathrm{c}}\right)^{0.5}$ for a Berkovitch indentor [10]. Therefore, by measuring $c$ for different loads and plotting $\chi F / c^{3 / 2}$ versus $c^{0.5}$, we can determine $K_{\mathrm{Ic}}$ and $\sigma_{\mathrm{r}}$.

To obtain interfacial toughness $K_{\text {int }}$, Rosenfeld et al. [11] provided a method based on the relationship between the size of the delaminated area and the corresponding load:

$K_{\text {int }}=\frac{0.792 H_{\mathrm{c}} \sqrt{\left(1-v_{\mathrm{c}}\right)^{2} e}}{1+v_{\mathrm{c}}+\frac{2\left(1-v_{\mathrm{c}}\right) H_{\mathrm{c}} \phi_{\mathrm{d}}^{2}}{F}}$

with $e$, coating thickness and $\Phi_{\mathrm{d}}$ the diameter of delamination area.

\subsubsection{Energy-based approach}

Malzbender and de With [4] suggested a method based on the energy dissipated during indentation which is equivalent to the area between the loading and unloading curves. By plotting the dissipated energy $U$ as a function of maximum load $F$ during indentation, it is possible to separate the different events. The energy dissipated into chipping $U_{\mathrm{c}}$ and delamination $U_{\mathrm{d}}$, gives an estimation of the fracture energy, respectively, of coating $\Gamma_{\mathrm{c}}$ and interface $\Gamma_{\mathrm{int}}$

$\Gamma_{\mathrm{c}}=\frac{U_{\mathrm{c}}}{3 \pi e \phi_{\mathrm{c}}}$,

$\Gamma_{\text {int }}=\frac{U_{\mathrm{d}}}{\pi \phi_{\mathrm{d}}^{2}}$.

Then, the coating and interface toughness can be determinated using

$K=\sqrt{\Gamma E}$ with $\left(\Gamma_{\mathrm{c}}, E_{\mathrm{c}}\right)$ for $K_{\mathrm{Ic}}$ and $\left(\Gamma_{\mathrm{int}}, E_{\mathrm{int}}\right)$ for $K_{\text {int }}$. The interfacial modulus $E_{\text {int }}$ is defined in Ref. [12].

These methods have been applied to our coatingssubstrates systems. Fig. 1 shows the indentation curve for the A1 system. The three events occurring during indentation induce changes observed on the loading curve. Cracking, delamination and chipping appears at approximately 15, 20 and $100 \mathrm{mN}$. In Fig. 2 are the Scanning Electron Microscopy (SEM) images of the indentation prints at different maximum load. At $20 \mathrm{mN}$ (Fig. 2(a)), radial cracks can be observed and white areas indicate that the delamination have just begun. With one delaminated and two chipped parts, the image for a load of $100 \mathrm{mN}$ (Fig. 2(b)) shows the transition between delamination and chipping. On the last image, for $F=650 \mathrm{mN}$ (Fig. 2(c)), we clearly evidence the three chipped areas.

Fig. 3 shows the graph of $\chi F / c^{3 / 2}$ as a function of $c^{0.5}$ corresponding to the A1 system. The intercept with the ordinate axis and the slope give respectively coating toughness $K_{\mathrm{Ic}}$ and residual stress $\sigma_{\mathrm{r}}$. The values obtained are: $K_{\mathrm{Ic}}=0.5 \pm 0.1 \mathrm{MPam}^{1 / 2}$ and $\sigma_{\mathrm{r}}=121 \pm 25 \mathrm{MPa} . \sigma_{\mathrm{R}}$ value implies tensile stresses. The energetic approach previously described has been used for this system. The values of $U$ as a function of indentation load $\mathrm{F}$ are shown in Fig. 4. The dissipated energies during chipping and delamination are respectively $U_{\mathrm{c}}=49 \pm 5 \mathrm{~nJ}$ and $U_{\mathrm{d}}=10 \pm 1 \mathrm{~nJ}$. This resulted in fracture energies of $\Gamma_{\mathrm{c}}=26 \pm 2 \mathrm{~J} / \mathrm{m}^{2}$ for the coating and $\Gamma_{\mathrm{int}}=67 \pm 7 \mathrm{~J} / \mathrm{m}^{2}$ for the interface. The diameters of chipped and delami-

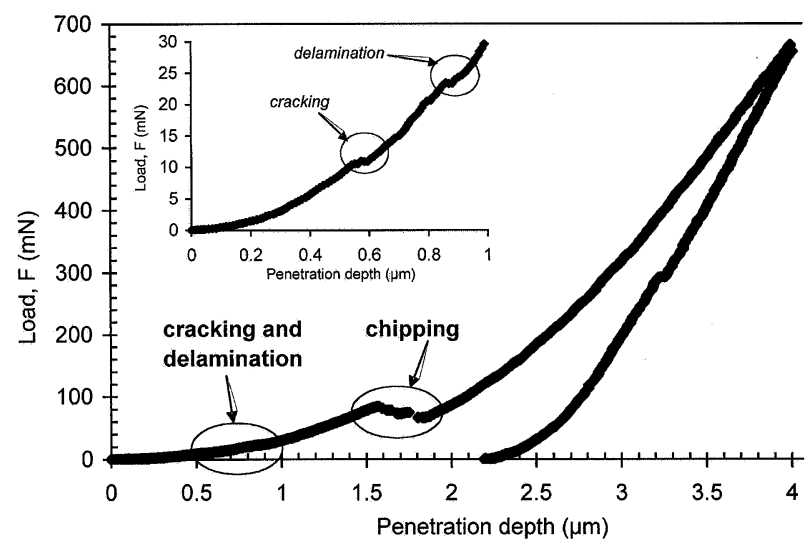

Fig. 1. Load-penetration depth curve for A1 system. Inset: details of cracking and delamination area. 

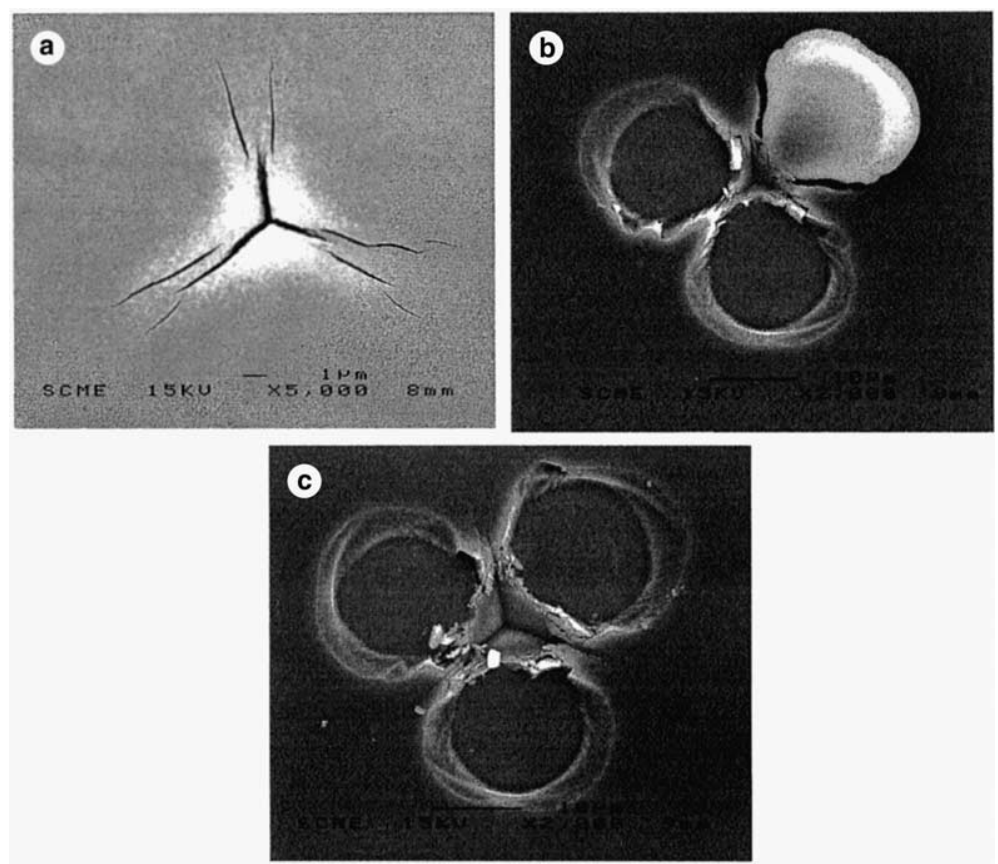

Fig. 2. SEM images of $\mathrm{A} 1$ system indentation prints: (a) $F=20 \mathrm{mN}$; (b) $F=100 \mathrm{mN}$ and (c) $F=650 \mathrm{mN}$.

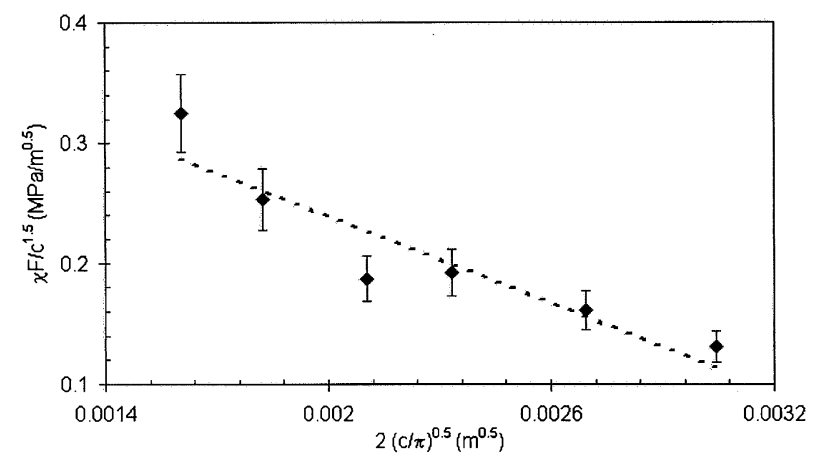

Fig. 3. $\chi F / c^{3 / 2}$ as a function of $c^{0.5}$ for A1 system.

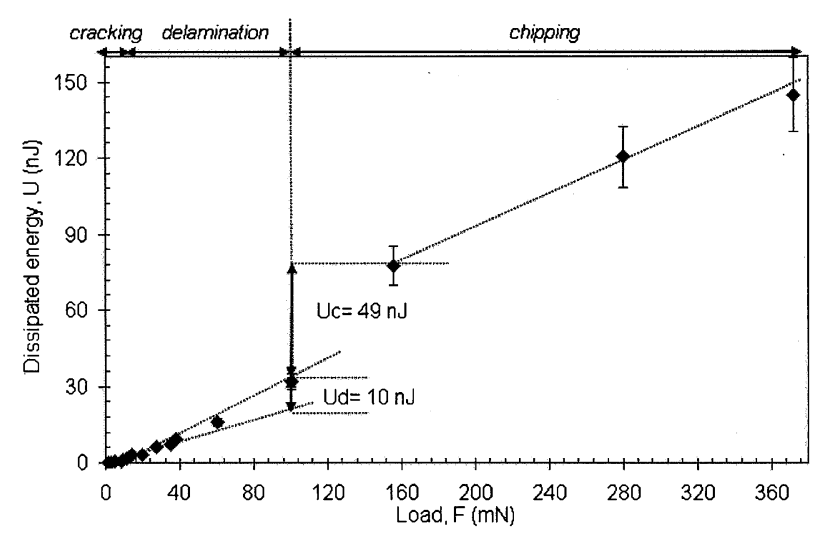

Fig. 4. Dissipated energy $U$ as a function of load for A1 system.

nated areas are $\Phi_{\mathrm{c}}=19.7 \pm 0.2 \mu \mathrm{m}$ and $\Phi_{\mathrm{d}}=6.9 \pm$ $0.2 \mu \mathrm{m}$, respectively. Finally, the values of toughness are $K_{\mathrm{Ic}}=0.7 \pm 0.1 \mathrm{MPam}^{1 / 2}$ for the coating and $K_{\text {int }}=1.5 \pm 0.2 \mathrm{MPam}^{1 / 2}$ for the interface. For this system, the interfacial toughness $K_{\text {int }}$ is also obtained with the geometrical method provided by Rosenfeld [12] and based on the size of delaminated area. The value obtained with this method is $K_{\text {int }}=1.3 \pm 0.2 \mathrm{MPam}^{1 / 2}$.

The same analysis is done for the A2 system. Fig. 5 shows the graph $\chi F / c^{3 / 2}$ versus $c^{0.5}$. For this system, cracking and delamination are observed but not chipping (due to the load limits of our instrument). It gives $K_{\mathrm{Ic}}=0.6 \pm 0.2 \mathrm{MPam}^{1 / 2}$ and $\sigma_{\mathrm{r}}=157 \pm 28 \mathrm{MPa}$. The value of interfacial toughness (by geometrical way) is $K_{\text {int }}=0.31 \pm 0.05 \mathrm{MPam}^{1 / 2}$ with a diameter of delaminated area of $\Phi_{\mathrm{d}}=6.4 \pm 0.2 \mu \mathrm{m}$. To avoid problems due to the load limit, a new instrument is now in progress, based on a modified traction INSTRON machine which permits to reach much more important loads.

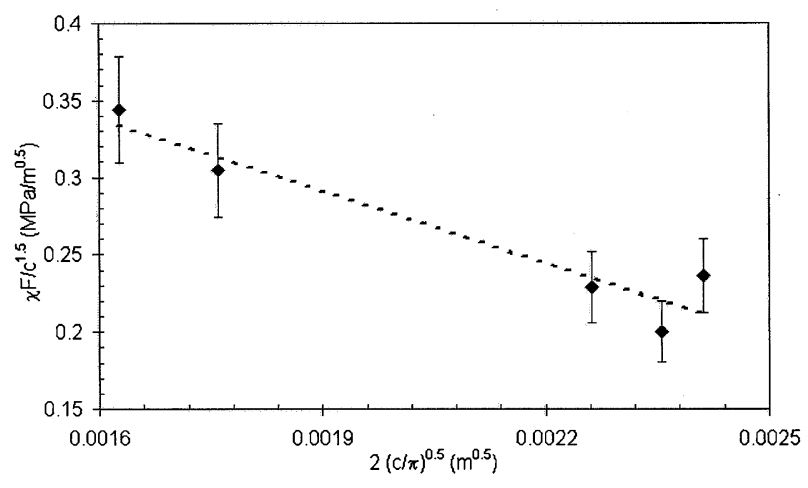

Fig. 5. $\chi F / c^{3 / 2}$ as a function of $c^{0.5}$ for $\mathrm{A} 2$ system. 


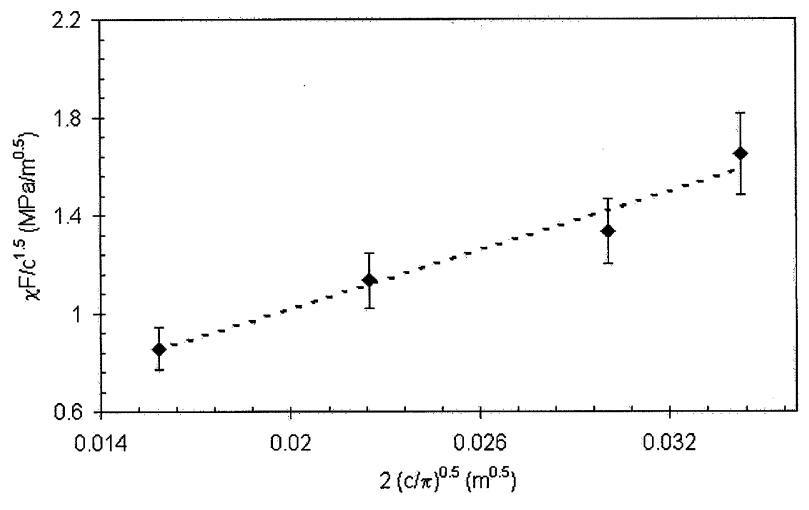

Fig. 6. $\chi F / c^{3 / 2}$ as a function of $c^{0.5}$ for B system.

For the B system, no delamination and chipping are evidenced. Cracks are observed but measured with difficulties because of the large elastic recovery which deforms the print. Only mechanical properties of coating can be inferred. Fig. 6 shows the graph of $\chi F / c^{3 / 2}$ as a function of $c^{0.5}$ for the B system. It permits to obtain $K_{\mathrm{Ic}}=0.21 \pm 0.05 \mathrm{MPam}^{1 / 2}$ and $\sigma_{\mathrm{r}}=-40 \pm 10 \mathrm{MPa}$. This result implies compressive residual stresses.

For easier reading and comparison, all the results are collected in Table 1 .

\section{Discussion}

\subsection{Hardnesss and elastic modulus}

As measurements have been performed at indentation depth lower than $10 \%$ of coating thickness, hardness and elastic modulus values do depend neither on substrate type nor on coating thickness. However, $H_{\mathrm{c}}$ and $E_{\mathrm{c}}$ values obtained for A1 system (silicon substrate) are larger than those of $\mathrm{A} 2$ system (glass substrate). Coatings have been heat treated at $250^{\circ} \mathrm{C}$ and one possible explanation for lower mechanical properties is the diffusion of sodium ions from the soda lime glass substrate into the coating. Previous works [13] show that sodium ions diffuse very rapidly into the coating even for short time of heat treatment. For long time of heat treatment, they can accumulate at the coating surface, disturbing hardness and elastic modulus measurements. To confirm this assumption, same measurements are in progress on fused silica.

Although coating A has a highly mineral nature, its elastic modulus is much lower than the silica one (69 $\mathrm{GPa})$. There is an effect of organic part which induces a decrease of network reticulation and then an increase of network flexibility. Moreover, this result can also be due to the incomplete condensation of silanols groups because of a low heat treatment temperature [14]. A decrease of inorganic network connectivity because of organic groups has a great influence on mechanical properties. This result is widely observed in hybrid [1].

Hardness and elastic modulus of B system are much lower than these of A systems. Due to its composition (MAPTMS and MAA), the B coating contains not only a more important quantity of organic matter but also an organic network. This latter completely drives elastic and plastic properties and leads to a behavior close to polymers one.

\subsection{Residual stress and coating toughness}

Residual stresses value of the A coating indicates that it undergoes a tensile stress. They can appear at different steps. First, after deposition, due to the solvent evaporation, the film undergoes shrinkage and the substrates sets against this shrinkage. They also can be due to the densification treatment. Finally, residual stresses can appear during cooling due to the thermal expansion coefficient mismatch between coating and substrate. We know from literature that thermal expansion coefficient is higher for soda lime glass $\left(9 \times 10^{-6}{ }^{\circ} \mathrm{C}^{-1}\right)$ than for silicon $\left(3 \times 10^{-6}{ }^{\circ} \mathrm{C}^{-1}\right)$. Even if the $\sigma_{\mathrm{r}}$ values are close for $\mathrm{A} 1$ and $\mathrm{A} 2$ systems (regarding to uncertainty), our results seems to show that coating on glass is more stressed than on silicon. More experiments are required to confirm this tendency and to obtain coating thermal expansion coefficient estimation. Finally, it is worth noting that the residual stresses obtained for the A coating are slightly higher than that of vitreous silica mechanical resistance in tension (about $100 \mathrm{MPa}$ ).

Unlike in A systems, residual stresses in the B coating are compressive. In this system, the densification heat treatment is replaced by UV curing of organic parts. Moreover, we previously evidenced that UV curing leads to a coating expansion [5]. This effect puts the coating in compression. As the final result is compressive residual stresses, it means that drying shrinkage effect is far lower than UV curing one.

The $K_{\mathrm{Ic}}$ values for $\mathrm{A} 1$ and $\mathrm{A} 2$ systems are in good agreement each other and a bit lower than the silica one $\left(K_{\text {Ic silica }}=0.75 \mathrm{MPam}^{1 / 2}\right)$. In the same way, the hardness and elastic modulus values are low compared to silica ones. However, even if bonds density of A system is lower than dense silica because of methyl groups and non-condensed $\mathrm{Si}-\mathrm{OH}$ [15] and taking into account the measurements accuracy, the required energy to break the material seems to be on a same order.

For A1 system, a slightly difference exists between the $K_{\text {Ic }}$ values respectively obtained with geometrical and energetical methods. The overestimation induced by energetical way is due to the substrate effect. Indeed, this method uses coating chipping and then requires high indentation loads. The substrate influence has to be taken in account. A way (proposed by Malzbender [4]) 
to have a good approximation is to extrapolate the energy data to infinite coating thickness.

The B system exhibits a low $K_{\text {Ic }}$ value $(0.21 \pm$ $\left.0.05 \mathrm{MPam}^{1 / 2}\right)$. In this coating, the hybrid precursors (MAPTMS and Zr-MAA) are network formers. The polycondensation of MAPTMS mineral entities induces a silica network and the photopolymerization of MAPTMS and MAA methacrylate groups induces an organic network close to PMMA. Moreover, the Zr-MAA precursor leads to the formation of $\mathrm{Zr}-\mathrm{O}-\mathrm{Zr}$ clusters [16] and $\mathrm{Zr}-\mathrm{OH}$ groups. With this texture, we might expect a $K_{\text {Ic }}$ value closer than those of polymers (PMMA for example, $K_{\mathrm{Ic}}=1.3 \mathrm{MPam}^{1 / 2}$ ) or at less a value between silica and PMMA ones. Considering that B coating has a highly organic nature, we can assume that we are studying the fracture of an elastoplastic material. In this case, the dissipated energy during fracture is the energy required to generate two surfaces but also consider the plastic deformation at the crack tip. Not taking this plastic deformation into account (as in the geometrical method), induces underestimated $K_{\text {Ic }}$ values. We might confirm this assumption with experiments at higher load which permit to obtain the fracture energy directly from indentation curves. The $K_{\text {Ic }}$ values might be compared more accurately.

Moreover, as previously explained, the cracks have been difficult to observe and then to measure. Due to the geometry of final print, cracks length has probably been overestimated leading to an underestimation of $K_{\mathrm{Ic}}$ and $\sigma_{\mathrm{r}}$. For example, a $c$ overestimation of $30 \%$ induces $K_{\mathrm{Ic}}$ and $\sigma_{\mathrm{r}}$ underestimations of, respectively, $70 \%$ and $100 \%$.

\subsection{Interfacial toughness}

In the A coating, interfacial fracture toughness is lower for A2 system (glass substrate) than for A1 system (silicon substrate). This result is probably in relation with two effects: the first one is the omission of residual stress in the Rosenfeld's method used to calculate $K_{\text {int }}$. These higher residual stresses in A2 system could explain a lower $K_{\text {int }}$ value. The second effect is the diffusion of sodium ions previously mentioned. This diffusion could be responsible of $\mathrm{Si}-\mathrm{O}-\mathrm{Si}$ breaking at the interface. In any case, the values of $K_{\text {int }}$ express the global adhesion between coating and substrate taking into account the system history. In these conditions, the results obtained for A coating seems to show a best adhesion on silicon.

\section{Conclusion}

Nanoindentation technique has been used to estimate mechanical properties of hybrid coatings on substrates.
Hardness and elastic modulus have been determinate from indentation curves at small load values. At higher load values, coating toughness and residual stress as well as interface toughness were estimated from cracks, delamination and chipping occurring in the coating on the basis of geometrical and energetical analyses. The two kinds of coating which have been studied, have different structure: one has a highly mineral structure and the other one contains an important organic network. The first one reveals better general mechanical properties (lower residual stress, better adhesion, higher interfacial toughness) on silicon than on glass. Sodium ions, which are known to diffuse very rapidly from substrate to coating seems to have an important influence on mechanical properties. To confirm this assumption, same measurements are in progress on dense silica substrates. For the second one, the elastic modulus and hardness are comparable with those of polymers. On the contrary, coating toughness is lower. However, the $K_{\text {Ic }}$ values may be underestimated because of plastic deformation at crack tip which is not taken into account with the geometrical method. Moreover, the important difficulty to measure cracks length because of elastic recovery in this coating shows that the geometrical method is probably not the best way to obtain toughness values. Finally, residual stresses are tensile stresses in system A and compressive stresses in system B.

\section{References}

[1] P. Etienne, J. Phalippou, R. Sempere, J. Mater. Sci. 33 (1998) 3999.

[2] M. Oubaha, M. Smaïhi, P. Etienne, P. Coudray, Y. Moreau, J. Non-Cryst. Solids 318 (2003) 305.

[3] J. Malzbender, G. de With, J. Non-Cryst. Solids 265 (2000) 51.

[4] J. Malzbender, G. de With, Surf. Coatings Tech. 135 (2000) 60.

[5] P. Etienne, P. Coudray, Y. Moreau, J. Porque, J. Sol-Gel Sci. Tech. 13 (1998) 523.

[6] P. Etienne, S. Calas-Etienne, S. Portal, Phys. Chem. Glasses 42 (4/5) (2001) 320.

[7] J. Loubet, J.M. Georges, O. Marchesini, G. Meille, J. Tribol. 106 (1984) 43.

[8] W.C. Oliver, G.M. Pharr, J. Mater. Res. 7 (1992) 1564.

[9] D. Broek, Elementary Engineering Fracture and Mechanics, Kluwer Academic, Dordrecht, 1997.

[10] D.B. Marshall, B.R. Lawn, J. Am. Ceram. Soc. 60 (1977) 86.

[11] L.G. Rosenfeld, J.E. Ritter, T.J. Lardner, M.R. Lin, J. Appl. Phys. 67 (1990) 3291.

[12] J.W. Hutchinson, Z. Suo, Adv. Appl. Mech. 29 (1992) 63.

[13] F. Bel Hadj, R. Sempere, J. Phalippou, J. Non-Cryst. Solids 82 (1986) 417.

[14] C.J. Brinker, G.W. Scherer, Sol-gel Science, Academic, New York, 1990.

[15] H. Schmidt, H. Scholze, G. Tunker, J. Non-Cryst. Solids 80 (1986) 557.

[16] H. Krug, F. Teillantes, P.W. Oliviers, H. Schmidt, Proc. SPIE 1758 (1992) 448. 